SHORT COMMUNICATION

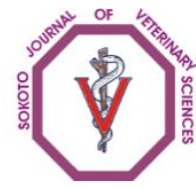

Sokoto Journal of Veterinary Sciences

(P-ISSN 1595-093X/ E-ISSN 2315-6201)

Umar \& Irefin /Sokoto Journal of Veterinary Sciences (2013) 11(2): 63-66.

http://dx.doi.org/10.4314/sokjvs.v11i2.10

\title{
Evaluation of the effects of intravenous anaesthesia using a combination of ketamine - medetomidine in Sahel goats
}

\author{
MA Umar* \& KE Irefin \\ Department of Veterinary Surgery \& Theriogenology, \\ Faculty of Veterinary Medicine \\ University of Maiduguri
}

*Correspondence: Tel.: 2348033499693, E-mail: ahmedtjumar@gmail.com

\section{Abstract}

The anaesthetic and cardiopulmonary effects of the combination of ketamine-medetomidine for total intravenous anaesthesia were evaluated in six sahel goats. The goats were administered a combination of ketamine $(5 \mathrm{mg} / \mathrm{kg})$ and medetomidine $(0.01 \mathrm{mg} / \mathrm{kg})$ intravenously. Baseline measurements of heart rate, respiratory rate and rectal temperature were taken prior to drug administration and repeatedly, at ten minutes interval after induction of anaesthesia until the end of anaesthesia. Heart rate decreased from baseline value of $73.5 \pm 5.7 \mathrm{beats} / \mathrm{minute}$ and reached its lowest value at 40 minutes ( $57.1 \pm 4.8$ beats/minute). Also respiratory rate decreased significantly from baseline value of $27.7 \pm 3.7$ breaths/minute reaching its lowest value of $19.0 \pm 4.6$ breaths/minute at 50 minutes. Onset of anaesthesia was fast $(1.2 \pm 1.5 \mathrm{~min})$ and mean anaesthesia time was $97.1 \pm 21.9 \mathrm{~min}$. Ketamine medetomidine intravenous injection produced effective anaesthesia, muscle relaxation and immobilization in sahel goats. Recovery from anaesthesia was without complication.

Keywords: Anaesthesia, Goats, Intravenous, Ketamine, Medetomidine.

Received: 04-01-2013

Accepted: 22-06-2013

\section{Introduction}

Current veterinary anaesthesia in large animals concentrates on the use of ketamine, guaifenesin, alpha $_{2}$ agonists, barbiturates and chloral hydrate (Yamashita et al., 2007). Advantages of intravenous anaesthesia include rapid and smooth induction of anaesthesia, little equipment requirements (needles, syringes, catheters), easy administration of drugs and achievement of balanced anaesthesia (Yamashita et al., 2007). Intravenous anaesthesia is indicated mostly for major surgery such as orthopaedic surgeries in animals including limb amputation, management, arthroscopy, obstetrical procedures like ceasarian section and orchidectomy in large animals (Hall et al., 2001; Umar et al., 2006; Kilic, 2008).

Ketamine has analgesic effect which is partly mediated by $\mathrm{N}$-Methyl-D-aspartate antagonistic activity in cats, dogs, rabbits and other small animals (Gaynor, 2002). Medetomidine is an alpha ${ }_{2}$ agonist which produces sedation, analgesia and muscle relaxation in veterinary practice. Medetomidine is an effective sedative in small animal practice (Sinclair, 2003) and horses (Umar et al., 2006; Yamashita et al., 2007).

Indeed, ketamine and medetomidine combinations have been found to provide excellent immobilization and muscle relaxation in a wide range of species of animals while the ability to reverse the sedative effect of alpha ${ }_{2}$ adrenoreceptor agonist has proved to be particularly useful (Hall et al., 2001). Kilic (2008) reported on cardio pulmonary, biochemical, and hematological changes after detomidinemidazolam - ketamine anaesthesia in calves and concluded that satisfactory anaesthesia and immobilization was produced for umbilical surgery, although some hypoxemia and respiratory acidosis occurred.

To date however, there is no report on the use of ketamine and medetomidine combination for intravenous anaesthesia in sahel goats. The aim of 
this study is to evaluate the effect of ketamine and medetomidine combination on total intravenous anaesthesia in sahel goats. Their effect on the heart rate, respiratory rate and rectal temperature were determined. Onset of effect, duration of anaesthesia, and time to standing position were also determined. However, their effects on haematological parameters have been published (Umar \& Wakil, 2013).

\section{Materials and methods \\ Animals}

Six sahel goats comprising of five females and one male with a mean ( \pm SD) body weight of $18.8 \pm 1.9$ (range $16-21 \mathrm{~kg}$ ) were used for the study. The goats were assessed to be healthy based on physical examination (heart and respiratory rates within normal) and hematological values that appeared normal and fecal examination showed absence of helminth eggs. Animal Care and Use Committee of University of Maiduguri approved the study.

\section{Drugs}

The drugs used for this study were a combination of ketamine hydrochloride injection at $5 \mathrm{mg} / \mathrm{kg}$ IV (Ketajet $50 \mathrm{mg} / \mathrm{ml}$, Rotexmedia, Trittua, Germany) and medetomidine at $0.01 \mathrm{mg} / \mathrm{kg}$ IV (Dormitor, Meiji, Seika Ltd, Tokyo, Japan).

\section{Experimental procedure}

The two drugs at dosages above were combined in a single syringe prior to slow IV injection.

The goats were observed during and after the intravenous injection of the drugs. The onset of the action of the drugs after injection; the time to spontaneous recumbency were noted.

Heart rate, respiratory rate and rectal temperature of the goats were obtained before the drugs were administered (baseline) and every 10minutes after the intravenous injection for the duration of anaesthesia. The heart rate (beats/minute) was assessed using a stethoscope (1 minute full count was done). Respiratory rate (breaths/minute) was assessed by visual observation of the thoracoabdominal movement (1 minute full count was done). The rectal temperature $\left({ }^{0} \mathrm{C}\right)$ was measured using a digital thermometer.

Analgesia was determined using pinprick with hypodermic needle applied at intervals over the skin of rib cage, flank, ventral abdomen and limbs. Positive response by the animal to the needle prick was defined as gross purposeful movement such as moving the head or leg withdrawal. The response was judged as negative when no reactions or movements were observed.

The anaesthetic indices calculated for each goat were: time to onset of anaesthesia, duration of anaesthesia and time to standing.

The calculated indices were defined as:

- Onset of anaesthesia: Is the time interval (in minutes) from the intravenous injection of the drug to the assumption of (lateral) recumbent posture by the goat.

- Duration of anaesthesia: Time interval (in minutes) from ketamine-medetomidine injection induced recumbency to assumption of sternal posture by the goat.

- Time to Standing: Is the time interval (in minutes) from assumption of sternal posture (recumbency) to when the goat is able to stand.

\section{Data analysis}

Data obtained are expressed as mean \pm SD of 6 goats. Mean heart rate, respiratory rate and rectal temperature measured were each compared to baseline (subsequent readings versus baseline value) using repeated-measures analysis of variance (Graphpad, 2000). Differences were accepted as significant at the probability level of less than 5 percent $(P<0.05)$.

\section{Results}

The onset of anaesthesia was fast with the combination of ketamine - medetomidine (1.2 \pm 1.5 $\min )$. The duration of anaesthesia was $97.1 \pm 21.9$ min. Time to standing from sternal recumbency was $5.3 \pm 3.3 \mathrm{~min}$. There was no response to pinprick during anaesthesia in all the goats with onset of analgesia of $5.4 \pm 2.0 \mathrm{~min}$ that lasted $81.5 \pm 6.4 \mathrm{~min}$. There was no significant decrease in the heart rate in the first 20 minutes. But after 30 minutes, there was a statistically significant decrease in the mean heart rate from the base line of $73.5 \pm 5.7$ beats/ minute to $65.0 \pm 4.5$ beats per minute, it reached lowest value at 40 minutes ( $57.1 \pm 4.8$ beats/minute). Thereafter it began increasing towards base line value. The mean heart rate returned to baseline value at 90 minutes post injection ( $76.7 \pm 7.3$ beats/minute) (Table 1 ).

There was a non-significant decrease in rectal temperature from baseline value of $38.7 \pm 0.9^{\circ} \mathrm{C}$ to $37.5 \pm 0.4^{\circ} \mathrm{C}$ after 90 minutes after intravenous injection. Respiratory rate decreased significantly 
Table 1: Effects of intravenous injection of ketamine- medetomidine at $5 \mathrm{mg} / \mathrm{kg}$ and $0.01 \mathrm{mg} / \mathrm{kg} \mathrm{IV}$, respectively on mean \pm SD heart rate, respiratory rate and rectal temperature in six Sahel goats

\begin{tabular}{llll}
\hline $\begin{array}{l}\text { Time Interval } \\
\text { (minutes) }\end{array}$ & $\begin{array}{l}\text { Heart Rate } \\
\text { (beats/min) }\end{array}$ & $\begin{array}{l}\text { Respiratory Rate } \\
\text { (breaths/min) }\end{array}$ & $\begin{array}{l}\text { Rectal Temperature } \\
\left({ }^{0} \mathrm{C}\right)\end{array}$ \\
\hline Baseline & $73.5 \pm 5.1$ & $27.7 \pm 3.7$ & $38.7 \pm 0.9$ \\
10 & $73.0 \pm 8.2$ & $26.3 \pm 4.7$ & $38.5 \pm 0.7$ \\
20 & $71.3 \pm 9.5$ & $27.1 \pm 5.9$ & $38.3 \pm 0.7$ \\
30 & $65.0 \pm 4.5^{*}$ & $21.0 \pm 3.3$ & $38.3 \pm 0.8$ \\
40 & $57.1 \pm 4.8^{*}$ & $19.5 \pm 5.0^{*}$ & $38.1 \pm 0.8$ \\
50 & $58.3 \pm 4.7^{*}$ & $19.0 \pm 4.6^{*}$ & $38.6 \pm 0.7$ \\
60 & $65.5 \pm 5.7^{*}$ & $20.0 \pm 4.4$ & $37.8 \pm 0.6$ \\
70 & $68.7 \pm 3.8$ & $23.4 \pm 3.9$ & $37.5 \pm 0.9$ \\
80 & $65.7 \pm 6.8$ & $23.8 \pm 2.4$ & $37.8 \pm 0.2$ \\
90 & $76.7 \pm 7.3$ & $25.0 \pm 1.4$ & $37.5 \pm 0.4$ \\
\hline
\end{tabular}

* Differ significantly $(\mathrm{P}<0.05)$ compared with baseline.

from the baseline value of $27.7 \pm 3.7$ breaths/minute to that observed at 50 minutes $(19.0 \pm 4.6$ breaths/minute). Thereafter, the value increases towards the baseline value (Table 1).

\section{Discussion}

The observed systemic effects of the combination of these drugs on heart rate in this study is a typical reaction as it was similarly reported following total intravenous anaesthesia using detomidinemidazoloam-ketamine in calves (Kilic, 2008) and Gweba et al. (2010) also reported heart rate decrease in goats administered xylazine for sedation. Afshar et al. (2005) also recorded decreased heart rate, rectal temperature and blood pressure during alpha $_{2}$ agonist - ketamine anaesthesia in goats. Medetomidine produces decrease in heart rate by activating central and peripheral $\alpha_{2}$ adrenoceptors (Sinclair, 2003; Yamashita et al. 2007).Respiratory rate decreased significantly towards the middle of this study but increased towards baseline at $90 \mathrm{~min}$. This contrasts the report of Kilic (2008) who reported that respiratory rate increased significantly with time following detomidine-midazolamketamine anaesthesia in calves undergoing umbilical surgery. The difference in species used and the fact that umbilical surgery was carried out in the previous study might be responsible for the increased respiratory rate reported. Also medetomidine that was used in this study produces more potent effects than other alhpa ${ }_{2}$ adrenoceptor agonists like detomidine. Afshar et al. (2005) reported non-significant change in respiratory rate in goats during xylazine-ketamine anaesthesia. Gweba et al. (2010) also reported decreased respiratory rate in goats following xylazine sedation. Rectal temperature decreased in this study, Afshar et al. (2005) and Gweba et al. (2010) similarly reported that rectal temperature decreased following systemic administration of $\alpha_{2}$ adrenoceptor agonist that was attributed to the depression of the hypothalamic thermoregulatory centre. The decrease in rectal temperature was also the result of a reduced basal metabolic rate and depression of thermoregulatory centre (Sinclair, 2003; Afshar et al., 2005).

This study revealed that medetomidine and ketamine combination for total intravenous anaesthesia in goats produced effective general anaesthesia. Onset of anaesthesia was rapid (1.2 \pm 1.5 minutes) and the mean anaesthesia time was $97.1 \pm 21.9$ minutes. This is more than double the anaesthesia time of 45 minutes in calves following detomidine-midazolam-ketamine combination as reported by Kilic (2008). Medetomidine that was used in the present study is a more potent sedative than detomidine and coupled with lack of surgery in this study these prolonged the anaesthesia in the goats. These two are responsible for the prolonged anaesthesia observed in the goats (Umar et al., 2006).

In conclusion, ketamine and medetomidine combination used for total intravenous anaesthesia produced effective anaesthesia in goats. The prompt anaesthesia coupled with manageable and good recoveries with no complications encountered suggests that ketamine and medetomidine combination for total intravenous anaesthesia has 
considerable promise as an injectable technique that can be used to produce anaesthesia in goats. However the cardiovascular side effects may preclude the use of the combination in critical and cardiovascular compromised patients.

\section{References}

Afshar FS, BaniAdam A \& Marashipour SP (2005). Effect of xylazine-ketamine on arterial blood pressure, arterial blood $\mathrm{pH}$, blood gases, rectal temperature, heart and respiratory rates in goats. Bulletin Veterinary Institute Pulawy, 49(4): 481- 484.

Gaynor JS (2002). Other drugs used to treat pain In: Handbook of Veterinary Pain Management (J.S. Gaynor \& W.W. Muir III, editors). Mosby, St Louis, Pp 251-260.

Graphpad (2000). Graph pad software: instant guide to choosing and interpreting. Statistical tests. Graph pad software Inc San Diego, USA.

Gweba M, Onifade, KI \& Faleke, OO (2010). Effect of xylazine sedation on some clinicophysiological and hematological parameters in Sokoto Red goats. Nigerian Veterinary Journal, 31(2). 177-181.

Hall LW, Clarke KW \& Trim CM (2001). Veterinary Anaesthesia (10th Edition). WB Saunders, London, Pp 113-131, 292-298.

Kilic N (2008). Cardiopulmonary, biochemical and hematological changes after detomidine, midozalam - ketamine Anaesthesia in
Calves. Bulletin Veterinary Instititute Pulawy, 52(3): 453-456.

Sinclair MD (2003). A review of physiological effects of $\propto_{2}$-agonists related to the clinical use of medetomidine in small animal practice. Canadian Veteterinary Journal, 44(11): 885897.

Umar MA \& Wakil Y (2013). Effects of the combination of ketamine and medetomidine anaesthesia on haematological parameters in Sahel goats. Sokoto Journal of Veterinary Sciences, 11(1): 66-69.

Umar MA, Yamashita, K, Kushiro, T, \& Muir, WW (2006). Evaluation of total intravenous anaesthesia with propofol or ketaminemedetomidine-propofol combination in horses. Journal of American Veterinary Medical Association, 228 (8): 1221-1227

Yamashita K, Wijayathilaka TP, Kushiro T, Umar MA, Taguchi K, Muir WW (2007). Anesthetic and Cardiopulmonary Effects of total intravenous anaesthesia using a midazolam, ketamine and medetomidine drug combination in Horses. The Journal of Veterinary Medical Science, 69(1): 7-13. 